\title{
Prediction of internet addiction based on information literacy among students of Iran University of Medical Sciences
}

\author{
Mostafa Langarizadeh ${ }^{1}$, Majid Naghipour ${ }^{2}$, Seyed Mohsen Tabatabaei ${ }^{2}$, Abbas Mirzaei ${ }^{3,4}$, Mohammad Eslami \\ Vaghar $^{5}$
}

${ }^{1}$ Ph.D. of Medical Informatics, Assistant Professor, Department of Health Information Management, School of Health Management and Information Sciences, Iran University of Medical Sciences, Tehran, Iran

${ }^{2} \mathrm{Ph}$.D. Candidate of Health Information Management, Department of Health Information Management, School of Health Management and Information Sciences, International Campus (IUMS-IC), Iran University of Medical Sciences, Tehran, Iran

${ }^{3}$ Ph.D. Candidate of Librarianship and Medical Information Sciences, Department of Library and Medical Information Sciences, School of Health Management and Information Sciences, Iran University of Medical Sciences, Tehran, Iran

${ }^{4}$ Medical Librarian, School of Dentistry, Tehran University of Medical Sciences, Tehran, Iran

${ }^{5}$ Assistant Professor, Department of Midwifery, Tehran Medical Sciences Branch, Islamic Azad University, Tehran, Iran

Type of article: Original

\begin{abstract}
Background: A considerable group of internet users consists of university users; however, despite internet benefits and capabilities, internet overuse is a threat to societies especially to young people and students.

Objective: The objective of this study was to determine the predictive role of information literacy in internet addiction among students of Iran University of Medical Sciences during 2016.

Methods: This analytical cross-sectional study was conducted in Iran University of Medical Sciences in 2016. Using stratified random sampling method, 365 students from different disciplines were selected. Measuring tools included the Information Literacy Questionnaire, the Yang Online Drug Addiction Scale and the General Health Questionnaire. The collected data were analyzed by Pearson product-moment correlation, independent samples ttest and multiple linear regression using SPSS version 22.

Results: According to this study, $31.2 \%$ of students had internet addiction $(29.9 \%$ were mildly addicted and $1.3 \%$ had severe addiction). There was a significant and inverse relationship between higher information literacy and internet addiction $(\mathrm{R}=-0.45)$ and $(\mathrm{p}<0.001)$. The predictor variable "Information literacy" explained $20 \%$ of the variation in the outcome variable "Internet addiction".

Conclusion: Students play a substantial role in promoting the cultural and scientific level of knowledge in society; the higher their information literacy, the lower the level of Internet addiction, and consequently the general health of society will improve. It seems that wise planning by authorities of Iran's universities to prevent internet addiction and to increase information literacy among students is needed.

Keywords: Information literacy, Internet addiction, Addictive behavior
\end{abstract}

\section{Introduction}

Today, the number of people who have become addicted to new technology or have extreme dependence on new technology, especially the Internet, is increasing day by day all over the world. This kind of addiction is one of the

\section{Corresponding author:}

Majid Naghipour, Department of Health Information Management, School of Health Management and Information Sciences, International Campus (IUMS-IC), Iran University of Medical Sciences, Tehran, Iran.

Tel: +98.9120256252, Fax:+98.2122601934, Email:mnaghipour@gmail.com

Received: October 08, 2017, Accepted: January 06, 2018, Published: February 2018

iThenticate screening: January 06, 2018, English editing: January 12, 2018, Quality control: January 15, 2018

This article has been reviewed / commented by five experts

(C) 2018 The Authors. This is an open access article under the terms of the Creative Commons Attribution-NonCommercialNoDerivs License, which permits use and distribution in any medium, provided the original work is properly cited, the use is non-commercial and no modifications or adaptations are made. 
most important problems in life along with new communication technologies (1). The Internet initially began to spread with the objective of collaboration, multiple accesses to resources and computational skills, and the feasibility of working in interdisciplinary fields of sciences and engineering; but since the mid-1990s, by providing services through web-based networking, the Internet has been considered as a global network. The dependence of all human activities on the Internet at a very large scale and in such a short time, represents the beginning of a new era of history in various fields of science, technology, and especially in the way we think, as humans. The growing body of research on internet addiction suggests that this problem is a psychosocial disorder characterized by tolerance, backwardness, emotional disturbances, and disruptive social relationships $(1,2)$. In addition to positive aspects such as access to new resources, being informed of research and the possibility of communication between researchers, this new communication tool also has harmful effects. On this issue, psychologists indicate a new type of addiction called internet addiction or virtual addiction. Internet addiction is a type of impulse control disorder which is called internet overuse in which other social activities of the user are undermined and it results in the weakness of performance in various domains such as occupational, scientific, professional, family, economic, and psychological realms and it also leads to the ignorance of relationships in real life including friends and family $(3,4)$. Internet dependence is a chronic, spreading and relapsing phenomenon associated with serious physical, financial, family, social and psychological harmful effects. It also leads to some disorders in social and individual functions, shyness, anxiety and imagination, and as a result, it brings about the neglect of family relationships, breakdown of social relationships, academic failure, and occupational problems. This behavioral dependence to the Internet is not only a disease or psychological complication, but is also a social problem even within the academic community $(5,6)$. Reviewing and detecting information needs, and punctual use of information produced by mass media and computers, illustrates the information literacy of a population that should be promoted $(7,8)$. Thus, as shown in Leung and Lee's study, internet addiction has a destructive role in the improvement of students' academic performance; besides, increasing information literacy is not only highly beneficial in education and research, but it also increases the speed of access to information and reduces the time of using the Internet and virtual space (9). In the past, the concept of addiction was based on medical patterns, and it was specifically defined as physical and psychological dependence on physical materials and not on behavioral patterns. Recent studies suggest that addiction can include widespread behavioral aspects (10). Given the importance of cyberspace pathology in community development in our country in recent years, information and communication technology has been taken into consideration, but there are still serious damages that need to be dealt with (11). Considering the number of internet users, Iran ranked $13^{\text {th }}$ in the world with nearly 56 million internet users, $70 \%$ of the population. Accordingly, based on the classification of the World Telecommunication Union in the use and access of the general public to the Internet, Iran is considered as a moderate country $(12,13)$. While the attentions have been mostly paid to internet addiction in academic and therapeutic environments, the development of international standards in the assessment and treatment of this disorder has been difficult. This can be due to cultural differences and confusion in the academic literature terminology of various communities of internet addiction (14). If a vulnerable person with a social and psychological background of tendency for drug abuse associates his or herself with a peer group to be exposed to drug addiction, he or she will be addicted to substance abuse. If this situation was adapted to the Internet and its virtual world, an emotional and diverse relationship could emerge and it could result in internet addiction (15). Some surveys have shown that internet addiction is even more gratifying than drug addiction, there are various statistics about the prevalence of internet addiction in different societies; however, the ratio of internet addicts has been estimated to be $2-5$ million per every 50 million of ordinary users, on average. In other words, it can be said that approximately 5-10 percent of internet users suffer from internet addiction $(4,16)$. The experts in the Internet domain have all emphasized the addictive nature of the Internet, especially in the student population $(17,18)$. Internet addiction is a global phenomenon with a variable prevalence rate of $5 \%$ to $25 \%$ among American, Chinese, Korean, British, Australian, Taiwanese, Japanese, Eastern European and Western European students (5, 18-20). Considering the various researches which have been conducted in Iran, and with regard to the increasing use of the Internet in society, especially among students, and considering the fact that the issue of internet addiction in Iranian universities has been discussed and its prevalence is moderate and lower than moderate, it seems that the increasing use of the Internet in Iran could affect the mental and physical health of students, and there will be problems with internet addiction in the future $(13,14,21)$. Researchers believe that today the problem of the prevalence of internet addiction in young people can be considered as a serious crisis in their individual and social life, and it has been argued in this regard that educational environments such as universities are fertile ground for internet addiction, and students are subject to internet addiction due to age requirements and the nature of their work, and it is anticipated that increasing the use of the Internet via cell phone services and the use of social networks in the future will increase the prevalence of internet addiction $(19,20)$. As shown in Lang and Lee's study, internet addiction has a destructive effect on the development of student academic performance. In addition to being a valuable service in 
education and research affairs, increasing information literacy increases the speed of access to information and it will reduce the time of using the Internet and virtual space (9). Investigating and recognizing the information needs, and timely use of information generated by mass media tools and computers, indicates the information literacy of individuals. With regard to the fact that information literacy is a set of skills in order to be able to recognize the information needs as well as the ability to purposefully use effective information resources, it is considered as an individual empowerment factor in purposeful use of information resources (9). Considering the effective role of information literacy and the destructive effect of internet addiction on the development of student academic performance, and regarding the importance of students as a leading group in societies, it is necessary to investigate the scientific consideration. The researcher's preliminary study showed that the relationship between information literacy and internet addiction among Iranian youths and students has not been investigated so far; therefore, considering the research gap in Iran, it is necessary that the level of information literacy as an important factor and variable, be investigated regarding the effect on students' internet addiction. Moreover, according to previous studies, which have shown that the increase in internet addiction leads to a decrease in public health $(5,10,18,20)$, this study primarily aims to determine the status of information literacy and the internet addiction rate and the relationship between these two variables among the students, and in the next step, it seeks to confirm previous studies and prove that internet addiction affects general health, and information literacy can indirectly contribute to this.

\section{Material and Methods}

\subsection{Research design and participants}

This analytical cross-sectional study was conducted in 2017 on Iran University of Medical Sciences students. In this study for the population of 6,500 university students the sample size was determined as 362 , using the Morgan table. Prior to determining sample size, 380 questionnaires were distributed among the population to prevent the loss of cases due to return of questionnaires, and finally 365 questionnaires were filled out and analyzed.

\subsection{Inclusion criteria}

The criteria for entering the study included studying at Iran University of Medical Sciences for at least one year, being a student in associate, bachelor, master or Ph.D. courses, and willingness to participate in the study. The dismissal criteria from the study included unwillingness to participate in the study or any defect in completing the data gathering tool.

\subsection{Instrument and data collection}

Data collecting tools contained three questionnaires namely, Information Literacy Questionnaire, Yang Online Drug Addiction Scale and General Health Questionnaire (GHQ-28). At the beginning of the Information Literacy Questionnaire, demographic characteristics of the subjects and eight questions about their personal characteristics (including age, gender, marital status, field of study, place of residence, type of internet connection and internet usage during 24-hours a day) were asked. The Information Literacy Test was used in the first part. The reliability and validity of the Information Literacy Test (ILT) has been confirmed in numerous foreign studies (22, 23), however, due to the cultural, educational, and social differences in Iran, a domestic questionnaire, which was approved in several studies, was used (24-26). Test-retest method was used to reevaluate the reliability of this tool, which was confirmed. All the items in this questionnaire were closed response format with a five-point Likert scale ranging from one as "totally disagree" to five as "strongly agree". The Kimberley Young's Internet Addiction Questionnaire is a standard questionnaire. It consists of 20 items and is evaluated using the Five Point Likert Scale (rarely, sometimes, often, frequently, and always). The minimum obtained score of this questionnaire is 20 and the maximum is 100 . According to the scores, participants are categorized into the three groups of non-addicted to the Internet (scores between 20 and 49), exposed to internet addiction (scores between 50 and 79) and addicted to the Internet (scores between 80 and 100). This questionnaire is a standard questionnaire and its validity have been confirmed. The reliability of this questionnaire has been reported in previous studies with Cronbach's alpha of more than 0.8 (27-29). The General Health Questionnaire (GHQ-28) is a standard tool with 28 questions. It is classified into four domains of physical symptoms, anxiety symptoms, social dysfunction and depression. In the Likert scoring method used in this study, the score of each question was from zero to three; therefore, the total score will vary from 0 to 84. Higher scores indicate a worse general health condition of participants. This questionnaire has been used in many studies within Iran, and its validity and reliability have been confirmed $(30,31)$. 


\subsection{Statistical analysis}

Data analysis was done using descriptive and inferential statistics (mean, standard deviation, absolute frequency and relative frequency) in order to compare the status of general health in the present study. The first part of the questionnaire (demographic information) is described and summarized in a table using descriptive statistics. Moreover, inferential statistics of Pearson product-moment correlation, independent samples t-test, and multiple linear regression were used for data analysis which was done using IBMC SPSS $\odot$ Statistics version 22 (IBMC) Corp., Armonk, NY, USA).

\subsection{Ethics of research}

The present article is the outcome of a research project (No. 26893) approved by Iran University of Medical Sciences and licensed by the Ethics Committee (No. IR-IUMS-REC-1395-26893).

\section{Results}

In the present study, out of 365 participants $35.9 \%$ were male participants and $64.1 \%$ were female. The mean age of participants was 24 years, varying from 19 to 28 years. According to Table 1, the majority of them were bachelor students $(50.1 \%$ ), while master students were $31 \%$, general medical students contained $12.9 \%$, and $6 \%$ of participants comprised of Ph.D. students. Table 2 depicts the status of internet addiction in which most of the participants were healthy (68.8\%), but about $29.9 \%$ were exposed to be addicted to the Internet and $1.3 \%$ had internet addiction. The total number of mild and severe addiction was $31.2 \%$. Using Kolmogorov-Smirnov statistical tests, it was found that the data have a normal distribution $(\mathrm{p}=0.20)$. According to the descriptive statistics of each dimension of information literacy for 365 students, the information needs with a mean of 33.26 5.73 , information location with an average of $26.85 \pm 6.07$, an evaluation of information with a mean of $39.08 \pm 8$, information effective usage with an average of $26.19 \pm 5.58$, and the total information literacy scores with a minimum of 42 and a maximum of 175 had an average of $125.39 \pm 21.16$. After classifying the information literacy into three groups of low, moderate and high literacy, the total score average of information literacy was determined as 125.39 so it was considered in the moderate range. Most students (about 60\%) had moderate information literacy. According to the results of Pearson product-moment correlation in Table 2, there was a significant relationship between information literacy and internet addiction among students of Iran University of Medical Sciences at alpha level of 0.05 ( $p<0.001$ and correlation coefficient $=-0.45$ ). So, for $95 \%$, it can surely be said that there was a reverse and significant relationship between student's literacy and internet addiction. Thus, the students with higher information literacy were less likely to be addicted to the Internet. The findings suggested that the information literacy variable alone predicted $22 \%$ of internet addiction (Table 3). As seen in Table 4, the mean and standard deviation of the scores from the general health questionnaire were obtained $20.31 \pm 5.973$ in the group of non-addicted to the Internet. Whereas, the mean and standard deviation of general health questionnaire for the subjects exposed to Internet addiction and those with internet addiction were $25.59 \pm 6.83$. Based on the data of independent-samples t-test, in all dimensions among the non-addicted group and exposed to internet addiction group, the general health score demonstrated statistically significant difference $(\mathrm{p}<0.001)$. Furthermore, Table 4 shows that according to that test, a significant difference was seen in the mean of general health score for dimensions of physical disorder, depression, anxiety and social function (respectively $\mathrm{p}<0.001, \mathrm{p}=0.003, \mathrm{p}<0.001, \mathrm{p}<0.001$ ).

Table 1. Frequency distribution of the students according to some personal characteristics

\begin{tabular}{|c|c|c|c|c|}
\hline \multicolumn{3}{|l|}{ Personal characteristics } & $\mathrm{n}$ & $\%$ \\
\hline \multirow[t]{2}{*}{ Gender } & \multicolumn{2}{|l|}{ Female } & 234 & 64.1 \\
\hline & \multicolumn{2}{|l|}{ Male } & 131 & 35.9 \\
\hline \multirow[t]{4}{*}{ Program of study } & \multicolumn{2}{|l|}{ Bachelor students } & 183 & 50.1 \\
\hline & \multicolumn{2}{|l|}{ Master students } & 113 & 31 \\
\hline & \multicolumn{2}{|l|}{ General medical students } & 47 & 12.9 \\
\hline & \multicolumn{2}{|l|}{ Ph.D. students } & 22 & 6 \\
\hline \multirow[t]{2}{*}{ Marital status } & \multicolumn{2}{|l|}{ Single } & 41 & 11.2 \\
\hline & \multicolumn{2}{|l|}{ Married } & 324 & 88.2 \\
\hline \multirow[t]{3}{*}{ Level of internet addiction } & \multicolumn{2}{|l|}{ Non-addicted to Internet } & 251 & 68.8 \\
\hline & \multirow[t]{2}{*}{ Exposed to be addicted of Internet } & Mild addiction & 109 & 29.9 \\
\hline & & Severe addiction & 5 & 1.3 \\
\hline
\end{tabular}


Table 2. Correlation coefficient between information literacy and internet addiction among students of Iran University of Medical Sciences

\begin{tabular}{|l|l|l|l|}
\hline Correlations & & Internet addiction score & Information literacy score \\
\hline $\begin{array}{l}\text { Pearson product- } \\
\text { moment correlation }\end{array}$ & Internet addiction score & 1.000 & -.456 \\
\cline { 2 - 4 } & Information literacy score & -0.456 & 1.000 \\
\hline \multirow{2}{*}{ Sig. (1-tailed) } & Internet addiction score & 0.000 & 0.000 \\
\cline { 2 - 4 } & Information literacy score & 0.000 & 0.000 \\
\hline $\mathrm{n}$ & Internet addiction score & 365 & 365 \\
\cline { 2 - 4 } & Information literacy score & 365 & 365 \\
\hline
\end{tabular}

Table 3. The predictive rate of internet addiction based on the variable of information literacy via multiple linear regression

\begin{tabular}{|l|l|l|l|}
\hline Model & Beta & $\mathrm{t}$ & $\mathrm{p}$-value \\
\hline Information literacy score & -0.494 & -10.13 & $<0.001$ \\
\hline Marital status & 0.101 & 2.132 & 0.034 \\
\hline Gender of students & 0.086 & 1.845 & 0.066 \\
\hline Program of study & 0.032 & 0.665 & 0.507 \\
\hline Residency status & 0.065 & 1.365 & 0.173 \\
\hline $\mathrm{R}=0.469, \mathrm{r}^{2}=0.22$ & \multicolumn{2}{|l|}{} \\
\hline
\end{tabular}

Table 4. Mean and standard deviation of four dimensions of general health according to severity of internet addiction

\begin{tabular}{|l|l|l|l|}
\hline \multirow{2}{*}{ Dimensions of general health } & non-addicted to the Internet & addicted to the Internet & \multirow{2}{*}{ p-value } \\
\cline { 2 - 3 } & Mean \pm S.D & Mean \pm S.D & \\
\hline Physical disorder score & $6.22 \pm 2.608$ & $7.81 \pm 2.338$ & \\
\hline Depression score & $4.38 \pm 2.184$ & $5.58 \pm 2.070$ & 0.001 \\
\hline Anxiety score & $2.26 \pm 2.384$ & $8.93 \pm 1.865$ & $<0.001$ \\
\hline Social function score & $7.54 \pm 2.144$ & $3.71 \pm 3.524$ & $<0.001$ \\
\hline Total score of general health & $20.31 \pm 5.973$ & $25.59 \pm 6.838$ & $<0.001$ \\
\hline
\end{tabular}

\section{Discussion}

The Internet is one of the most important sources for accessing scientific literature in universities and scientific institutes by which students can meet their professional and personal goals (32). The findings of this study showed that there was a significant and reverse relationship between information literacy and internet addiction, and increasing of information literacy could reduce both the spent time in virtual space and the internet addiction. On the other hand, if the internet addiction was reduced, general health would be increased. The results of this study are consistent with many other studies conducted in this domain (5). According to Daglas et al. (2008), internet addiction is an extreme forced use of this tool that, if the person be deprived of, he/she becomes highly irritable, and it manifests itself with boredom behaviors and reduces the general health of the individual (33), in studies conducted by Ko et al. (2008), it has been shown that mood disorders such as depression, social isolation, and aggression are more prevalent in addicted internet users (34). A significant difference between internet addiction and general health dimensions (physical inability, depression, anxiety, and social function) was observed in this study, which confirms Daglas and Ko's study. Cao and $\mathrm{Su}$ (2007) in their study of Chinese teenagers showed that $88 \%$ of Chinese teenagers use the Internet, of which $2.4 \%$ are addicted to the Internet, which can affect their physical, psychological, and family life and also lead to depression (16), The results of their study are consistent with the current study. Nimz et al. (2005) also found a significant negative correlation between the general health of internet users and increasing hours of work on the Internet, and their results showed that there is a reverse and significant relationship between internet addiction and physical health, in a way that physical health in the group exposed to addiction and addicted is lower than normal people (35), and these study results are consistent with the results of the current study. In 2015, Wegmann et al. carried out a study on 334 students regarding internet literacy, information literacy and addictive use of the Internet and social networks. They suggested that promoting of individual skills such as high information literacy could be a preventive factor in the use of virtual networks and the Internet; eventually it could reduce internet addiction and it could have a positive effect on academic performance of students (1). The results of their study are consistent with the results of the present study. Another study which was done in 2017 by Chun et al. reviewed the relationship between information literacy and internet addiction among students of South Korea. They 
assessed the relationship between spent time on the Internet and the academic achievement of students. The results showed a positive relationship between internet literacy and academic achievement among students (36). The results of a survey conducted by Lemos et al. in 2016 declared that those who avidly used the Internet had high levels of depression and anxiety, and they had a lower level of self-esteem. Moreover, the gender significantly affected the results as boys were more dependent on the Internet than girls; however, in the present study there was no statistically significant difference in the level of internet addiction between boys and girls (37). According to Byun et al., internet addiction is an extremely forced use of this tool in which the user becomes highly irritable in the case of being deprived of it and exhibits bad tempered behavior. Moreover, in two studies of Ko et al. the results showed that mood disorders such as depression, social isolation and aggression were more prevalent among internet addicts than normal people $(34,39)$. One of the limitations of this study was the use of a questionnaire as a measurement tool that interview and content analysis method can be used in future studies for more accurate investigation. Only the students of Iran University of Medical Sciences were researched in this study. It is suggested that more studies be conducted at different universities in the medical and non-medical departments nationwide, and increase the sample sizes to achieve more accurate results.

\section{Conclusions}

According to the findings of this study, it was found that the level of internet addiction in students is moderate. The higher the information literacy, the level of internet addiction decreases, and the reduction of internet addiction will increase the general health of students. Therefore, information literacy indirectly affects increasing the general health of the students. Therefore, considering the importance of students as the leading group in communities and their important role in promoting the cultural and scientific level of individuals in the community, it is necessary for university authorities to plan and implement the required programs to increase the students' information literacy in the educational and research planning of the university in order to reduce the undesirable effects of using the Internet, and increase the overall health of the community. Since this study was carried out at a university, it is suggested that further studies with larger sample sizes be conducted in order to identify other effective variables in the field of internet addiction.

\section{Acknowledgments:}

The present article is the outcome of a research project (No. 26893) approved by Iran University of Medical Sciences and licensed by the Ethics Committee (No. IR-IUMS-REC-1395-26893). Moreover, it is sponsored by the Research Deputy of this university. Hereby, we are thankful to the Vice-Chancellor of the Faculty of Management and Medical Information who provided the opportunity that greatly assisted the research and also all those who helped us in this study.

\section{Conflict of Interest:}

There is no conflict of interest to be declared.

\section{Authors' contributions:}

All authors contributed to this project and article equally. All authors read and approved the final manuscript.

\section{References:}

1) Wegmann E, Stodt B, Brand M. Addictive use of social networking sites can be explained by the interaction of internet use expectancies, internet literacy, and psychopathological symptoms. J Behav Addict. 2015; 4(3): 155-62. doi: 10.1556/2006.4.2015.021. PMID: 26551905, PMCID: PMCPMC4627676.

2) Alipour J, Safari Lafti S, Askari Majdabadi H, Yazdiyani A, Valinejadi A. Factors affecting hospital information system acceptance by caregivers of educational hospitals based on technology acceptance model (TAM): A study in Iran. IIOAB Journal. 2016: 119-23.

3) Greenfield DN. Psychological characteristics of compulsive internet use: a preliminary analysis. Cyberpsychol Behav. 1999; 2(5): 403-12. doi: 10.1089/cpb.1999.2.403. PMID: 19178212.

4) Cao H, Sun $Y$, Wan $Y$, Hao J, Tao F. Problematic Internet use in Chinese adolescents and its relation to psychosomatic symptoms and life satisfaction. BMC public health. 2011; 11: 802. doi: 10.1186/1471-245811-802. PMID: 21995654, PMCID: PMCPMC3214169.

5) Tang CS, Koh YY. Online social networking addiction among college students in Singapore: Comorbidity with behavioral addiction and affective disorder. Asian J Psychiatr. 2017; 25: 175-8. doi: 10.1016/j.ajp.2016.10.027. PMID: 28262144. 
6) Ko CH, Yen JY, Chen CS, Yeh YC, Yen CF. Predictive values of psychiatric symptoms for internet addiction in adolescents: a 2-year prospective study. Arch Pediatr Adolesc Med. 2009; 163(10): 937-43. doi: 10.1001/archpediatrics.2009.159. PMID: 19805713.

7) Haruna $\mathrm{H}$, Tshuma $\mathrm{N}, \mathrm{Hu} \mathrm{X}$. Health Information Needs and Reliability of Sources Among Nondegree Health Sciences Students: A Prerequisite for Designing eHealth Literacy. Ann Glob Health. 2017; 83(2): 369-79. doi: 10.1016/j.aogh.2017.03.516. PMID: 28619414.

8) Karami M, Fatehi M, Torabi M, Langarizadeh M, Rahimi A, Safdari R. Enhance hospital performance from intellectual capital to business intelligence. Radiol Manage. 2013; 35(6): 30-5. PMID: 24475528.

9) Leung L, Lee PS. Impact of internet literacy, internet addiction symptoms, and internet activities on academic performance. Social Science Computer Review. 2012; 30(4): 403-18. doi: 10.1177/0894439311435217.

10) Floros G, Siomos K, Stogiannidou A, Giouzepas I, Garyfallos G. The relationship between personality, defense styles, internet addiction disorder, and psychopathology in college students. Cyberpsychol Behav Soc Netw. 2014; 17(10): 672-6. doi: 10.1089/cyber.2014.0182. PMID: 25225916.

11) Sadoughi F, Valinejadi A, Shirazi MS, Khademi R. Social Network Analysis of Iranian Researchers on Medical Parasitology: A 41 Year Co-Authorship Survey. Iran J Parasitol. 2016; 11(2): 204-12. PMID: 28096854, PMCID: PMCPMC5236097.

12) Rastegar DA, Bertram A, Sisson SD. Use of an internet-based curriculum to teach internal medicine residents about addiction. J Addict Med. 2010; 4(4): 233-5. doi: 10.1097/ADM.0b013e3181cc9fc7. PMID: 21769041.

13) Fatehi F, Monajemi A, Sadeghi A, Mojtahedzadeh R, Mirzazadeh A. Quality of Life in Medical Students With Internet Addiction. Acta Med Iran. 2016; 54(10): 662-6. PMID: 27888595.

14) Naseri L, Mohamadi J, Sayehmiri K, Azizpoor Y. Perceived Social Support, Self-Esteem, and Internet Addiction Among Students of Al-Zahra University, Tehran, Iran. Iran J Psychiatry Behav Sci. 2015; 9(3): e421. doi: 10.17795/ijpbs-421. PMID: 26576175, PMCID: PMCPMC4644622.

15) Schou Andreassen C, Billieux J, Griffiths MD, Kuss DJ, Demetrovics Z, Mazzoni E, et al. The relationship between addictive use of social media and video games and symptoms of psychiatric disorders: A largescale cross-sectional study. Psychol Addict Behav. 2016; 30(2): 252-62. doi: 10.1037/adb0000160. PMID: 26999354.

16) Cao F, Su L. Internet addiction among Chinese adolescents: prevalence and psychological features. Child Care Health Dev. 2007; 33(3): 275-81. doi: 10.1111/j.1365-2214.2006.00715.x. PMID: 17439441.

17) Leung L. Predicting Internet risks: a longitudinal panel study of gratifications-sought, Internet addiction symptoms, and social media use among children and adolescents. Health Psychol Behav Med. 2014; 2(1): 424-39. doi: 10.1080/21642850.2014.902316. PMID: 25750792, PMCID: PMCPMC4346000.

18) Park S, Lee Y, Jun JY. Differences in the relationship between traumatic experiences, self-esteem, negative cognition, and internet addiction symptoms among North Korean adolescent defectors and South Korean adolescents: A preliminary study. Psychiatry Res. 2017; 257: 381-5. doi: 10.1016/j.psychres.2017.07.078. PMID: 28818806, PMCID: PMC4804263.

19) Kuss DJ, Lopez-Fernandez O. Internet addiction and problematic Internet use: A systematic review of clinical research. World J Psychiatry. 2016; 6(1): 143-76. doi: 10.5498/wjp.v6.i1.143. PMID: 27014605, PMCID: PMCPMC4804263.

20) Kim D, Lee D, Lee J, Namkoong K, Jung YC. Association between childhood and adult attention deficit hyperactivity disorder symptoms in Korean young adults with Internet addiction. J Behav Addict. 2017; 6(3): 345-53. doi: 10.1556/2006.6.2017.044. PMID: 28786707, PMCID: PMC5700719.

21) Mohammadbeigi A, Valizadeh F, Mirshojaee SR, Ahmadli R, Mokhtari M, Ghaderi E, et al. Self-rated Health and Internet Addiction in Iranian Medical Sciences Students; Prevalence, Risk Factors and Complications. Int J Biomed Sci. 2016; 12(2): 65-70. PMID: 27493592, PMCID: PMCPMC4947091.

22) Boh Podgornik B, Dolničar D, Šorgo A, Bartol T. Development, testing, and validation of an information literacy test (ILT) for higher education. J Assoc Inf Sci Tech. 2016; 67: 2420-36. doi: 10.1002/asi.23586.

23) Cameron L, Wise SL, Lottridge SM. The development and validation of the information literacy test. Coll Res Lib. 2007; 68: 229-37. doi: 10.5860/crl.68.3.229.

24) Momeni M, Valizadeh S, Ghorbani R. A survey on the information literacy of final-year students studying at Semnan University of Medical Sciences (2012). Koomesh. 2014; 15(4): 502-10.

25) Keshavarz H, Givi E, Reza M, Vafaeian A, Khademian M. Information Literacy Self-efficacy Dimensions of Post Graduate Students: Validating a Persian Version Scale. Libri. 2017; 67(1): 75-86. doi: 10.1515/libri-2016-0092. 
26) Karimi Z, Ashrafi-rizi H, Papi A, Shahrzadi L, Hassanzadeh A. Effect of information literacy training course on information literacy skills of undergraduate students of Isfahan University of Medical Sciences based on ACRL standards. J Educ Health Promot. 2015; 4: 76. doi: 10.4103/2277-9531.171789. PMID: 27462618, PMCID: PMC4944610.

27) Pawlikowski M, Altstötter-Gleich C, Brand M. Validation and psychometric properties of a short version of Young's Internet Addiction Test. Comput Hum Behav. 2013; 29: 1212-23. doi: 10.1016/j.chb.2012.10.014.

28) Ranjbar H, Thatcher A, Greyling M, Arab M, Nasri N. Validation of the Persian Version of the Problematic Internet Use Questionnaire (PIUQ). Iran J Psychiatry. 2014; 9(4): 248-52. PMID: 25792994, PMCID: PMCPMC4361829.

29) Nastizai N. The relationship between general health and internet addiction. Zahedan J Res Med Sci. 2009; 11(1): 21-7.

30) Nazifi M, Mokarami H, Akbaritabar A, Faraji Kujerdi M, Tabrizi R, Rahi A. Reliability, validity and factor structure of the persian translation of general health questionnire (ghq-28) in hospitals of kerman university of medical sciences. J Fasa Univ Med Sci. 2014; 3: 336-42.

31) Khosravi A, Mousavi SA, Chaman R, Kish MS, Ashrafi E, Khalili M, et al. Reliability and validity of the Persian version of the World Health Organization-five well-being index. IJHS. 2015; 1: 9-17.

32) Al-Gamal E, Alzayyat A, Ahmad MM. Prevalence of Internet Addiction Internet Addiction and Its Association With Psychological Distress and Coping Strategies Among University Students in Jordan. Perspect Psychiatr Care. 2016; 52(1): 49-61. doi: 10.1111/ppc.12102. PMID: 25639746.

33) Douglas AC, Mills JE, Niang M, Stepchenkova S, Byun S, Ruffini C, et al. Internet addiction: Metasynthesis of qualitative research for the decade 1996-2006. Comput Hum Behav. 2008; 24: 3027-44. doi: 10.1016/j.chb.2008.05.009.

34) Ko CH, Yen JY, Chen CS, Chen CC, Yen CF. Psychiatric comorbidity of internet addiction in college students: an interview study. CNS Spectr. 2008; 13(2): 147-53. doi: 10.1017/S1092852900016308. PMID: 18227746.

35) Niemz K, Griffiths M, Banyard P. Prevalence of pathological internet use among university students and correlations with self-esteem, the General Health Questionnaire (GHQ), and disinhibition. Cyberpsychol Behav. 2005; 8(6): 562-70. doi: 10.1089/cpb.2005.8.562. PMID: 16332167.

36) Chun J, Shim H, Kim S. A Meta-Analysis of Treatment Interventions for Internet Addiction Among Korean Adolescents. Cyberpsychol Behav Soc Netw. 2017; 20(4): 225-31. doi: 10.1089/cyber.2016.0188. PMID: 28263660.

37) Lemos IL, Cardoso A, Sougey EB. Validity and reliability assessment of the Brazilian version of the game addiction scale (GAS). Compr Psychiatry. 2016; 67: 19-25. doi: 10.1016/j.comppsych.2016.01.014. PMID: 27095330.

38) Byun S, Ruffini C, Mills JE, Douglas AC, Niang M, Stepchenkova S, et al. Internet addiction: metasynthesis of 1996-2006 quantitative research. Cyberpsychol Behav. 2009; 12(2): 203-7. doi: 10.1089/cpb.2008.0102. PMID: 19072075.

39) Ko CH, Hsiao S, Liu GC, Yen JY, Yang MJ, Yen CF. The characteristics of decision making, potential to take risks, and personality of college students with Internet addiction internet addiction. Psychiatry Res. 2010; 175(1-2): 121-5. doi: 10.1016/j.psychres.2008.10.004. PMID: 19962767. 